\title{
Traditional Chinese patent medicines for cancer treatment in China: a nationwide medical insurance data analysis
}

\author{
Min Wu ${ }^{1}$, Peng Lu ${ }^{3}$, Luwen Shi ${ }^{1}$, Shao $\mathbf{L i}^{2}$ \\ ${ }^{1}$ Department of Pharmacy Administration and Clinical Pharmacy, School of Pharmaceutical Sciences, Peking University, \\ Beijing, China \\ ${ }^{2}$ MOE Key Laboratory of Bioinformatics and Bioinformatics Division, TNLIST/Department of Automation, Tsinghua University, \\ Beijing, China \\ ${ }^{3}$ Institute of Automation, Chinese Academy of Sciences, Beijing, China \\ Correspondence to: \\ Shao Li, e-mail: shaoli@mail.tsinghua.edu.cn \\ Luwen Shi, e-mail: shilu@bjmu.edu.cn \\ Keywords: traditional Chinese medicine, cancer treatment, medical insurance, nationwide survey, herb-drug network \\ Received: July 21, $2015 \quad$ Accepted: September 30,2015 Published: October 13, 2015
}

\section{ABSTRACT}

Based on the nationwide survey into inpatients' utilization of the health service covered by China's urban basic medical insurance from 2008 to 2010, we analyzed the use rate, cancer profile and combined use of anticancer Chinese patent medicines (CPMs) on 51,382 insured cancer patients by using statistical, bi-clustering and network methods. We found that $42.4 \%$ of 51,382 cancer patients used 33 anticancer CPMs, and $51.7 \%$ used 71 anticancer Western medicines (WMs). The CPMs were most often used in lung $(52 \%)$ and nasopharynx (52\%) cancer patients, and least in bladder cancer $(21 \%)$ and leukemia of unspecified cell type $(21 \%)$ patients. The cost per patient for all 33 anticancer CPMs was 2069RMB, lower than that of the WMs (3458RMB). The cancer profile of commonly used CPMs and WMs for the top 17 cancers ( $>500$ sampled patients) were provided, indicating anticancer CPMs had a broad spectrum of cancers and lacked selectivity in cancer treatment (CPM mean CV $=49 \%$; WM mean CV $=152 \%$ ). Moreover, $24.8 \%$ of the cancer patients used both CPMs and WMs, and CPM-WM combined use networks were constructed for four major cancers. This first nationwide analysis revealed the use characteristics and herb-drug combined use patterns of insurance covered anticancer CPMs in China. The study offers valuable information to guide future studies of the precision, safety and standard use of CPMs.

\section{INTRODUCTION}

Chinese patent medicines (CPMs), as a new fashion to modernize traditional Chinese medicine (TCM), play an increasingly important role in China's medical practice. CPMs are produced by modern manufacturing processes in forms such as capsules and injections [1]. CPMs, together with Western medicines (WMs) and Chinese herbal medicines, are the three categories of drugs in China's National Basic Medical Insurance Drug Catalogue (NBMIDC) [2], since China launched the National Basic Medical Insurance System in 1998. Anticancer CPMs is a special category in NBMIDC anticancer drugs. Recently, several hospitals reported that anticancer CPMs are increasingly being used in cancer treatment, and even growing faster than Western drugs [3-5]. Moreover, TCM has showed bright prospects not only in the discovery of anticancer drugs [6], but also in the systematic therapy for complex diseases [7]. With the wide use and increasing interest of CPMs in cancer treatment, a comprehensive and in-depth analysis for anticancer CPMs is urgently required.

To meet such urgent needs, we analyzed the data from the first nationwide survey into inpatients' utilization of health services covered by China's Urban Basic Medical Insurance from 2008 to 2010. This investigation was conducted by the China Health Insurance Research Association affiliated with the Ministry of Human Resources and Social Security of China. The health insurance data can provide rich information to describe the clinical care and drug use in a large scale $[8,9]$. Based on 51,382 insured cancer inpatients from the nationwide survey, we for the first time revealed the use characteristics as well as herb-drug combined use 
patterns in China, offering valuable information to improve the rational use of anticancer drugs in the future.

\section{RESULTS}

\section{Overall use of anticancer CPMs and WMs in sampled cancer patients}

Of the 51,382 hospitalized cancer patients (Table S1), 67.9\% (cost ratio $13.4 \%$ ) used CPMs, $42.4 \%$ (cost ratio 9.1\%; 2069 RMB cost per patient) used anticancer CPMs; $98.2 \%$ (cost ratio $86.4 \%$ ) used WMs, and $51.7 \%$ (cost ratio $18.6 \%$; 3458 RMB cost per patient) used anticancer WMs (Fig. 1A and 1B).
Overall, 44,447 patients (87\%) experienced 17 malignant cancers with each cancer having more than 500 cases (Table S2). 9 of the top 10 cancers are the same as those from a previously China national survey [10]. In top 17 cancers, use of 33 anticancer CPMs was highest in lung and nasopharynx cancer patients (both were 52\%), and was higher than those using anticancer WMs (44\% and 45\%). Anticancer CPMs were also more commonly used than anticancer WMs for liver cancer ( $20 \%$ more), kidney cancer ( $14 \%$ more), pancreatic cancer $(10 \%$ more $)$, and esophagus cancer ( $8 \%$ more). By contrast, anticancer CPMs were used least for bladder cancer and leukemia of unspecified cell type (both were 21\%) (Fig. 1C and 1D).
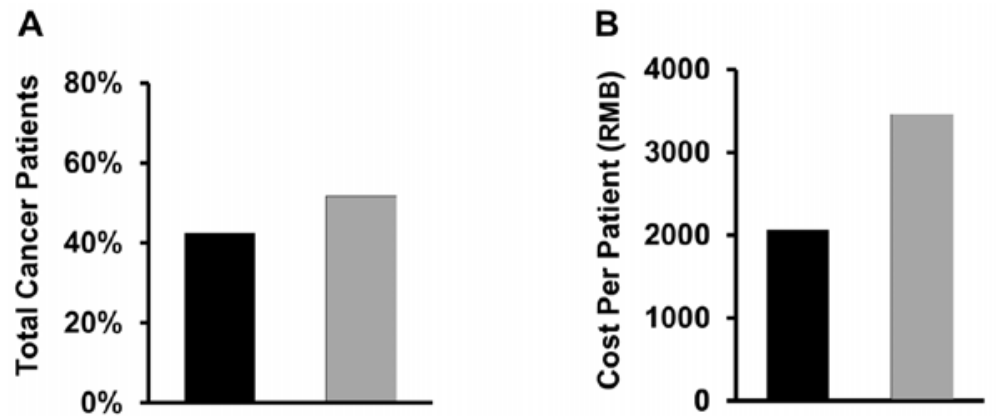

Anticancer CPMs

Anticancer WMs

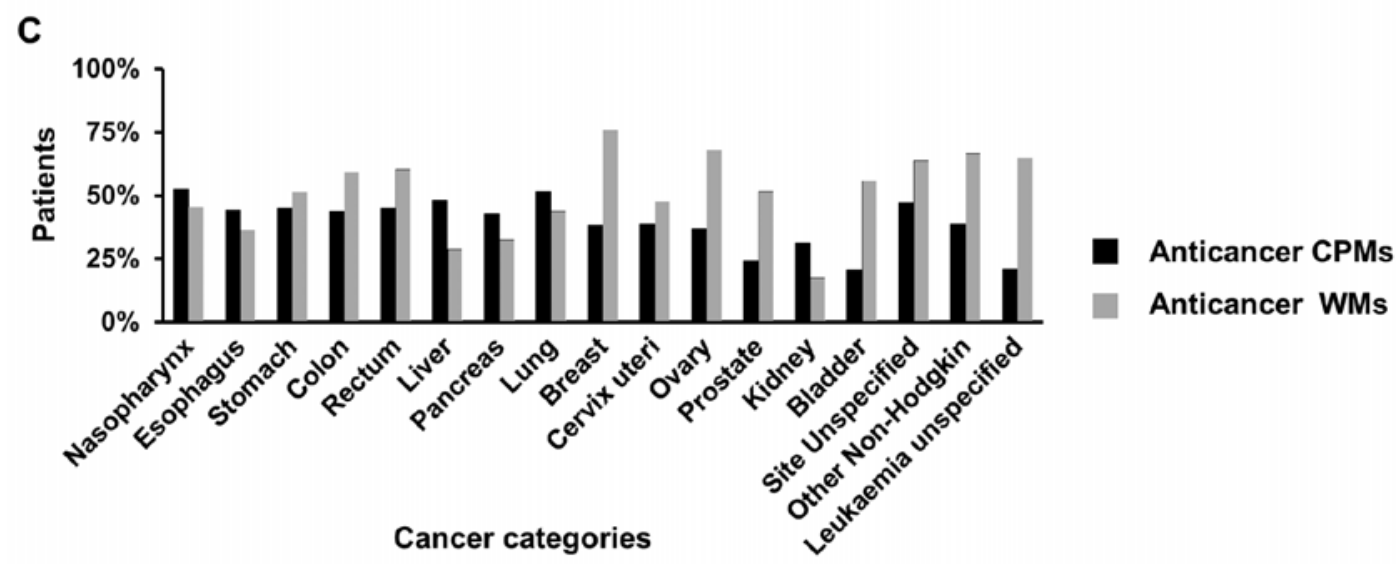

D

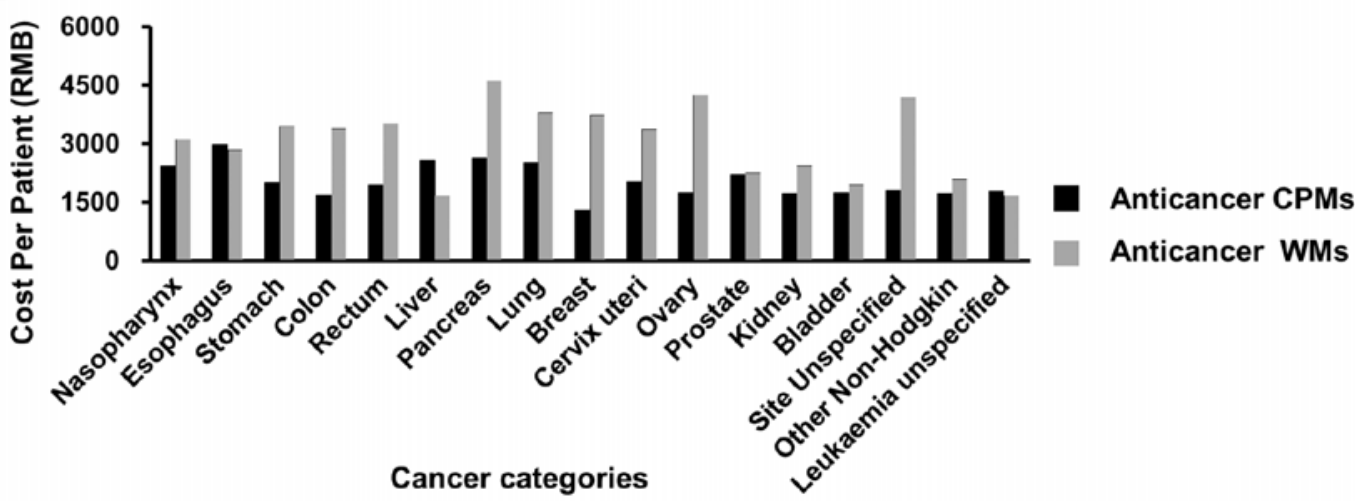

Figure 1. The overall use rate (A) and cost per patient (B) of 33 anticancer CPMs and 71 anticancer WMs, and their use rate (C) and cost per patient (D) in the top 17 cancers with a case number over 500.

(Continued) 

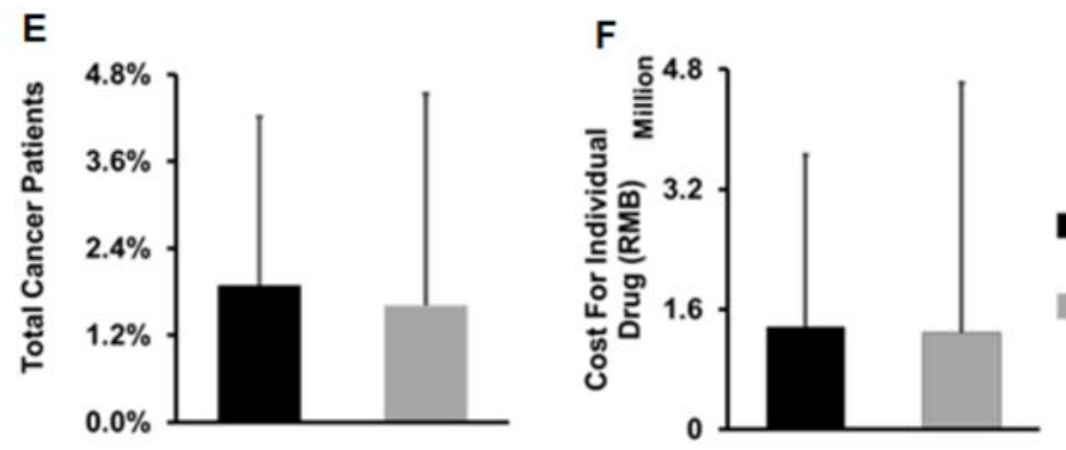

Individual Anticancer

CPMs ( $n=33$ )

Individual Anticancer

WMs $(n=71)$

G

H
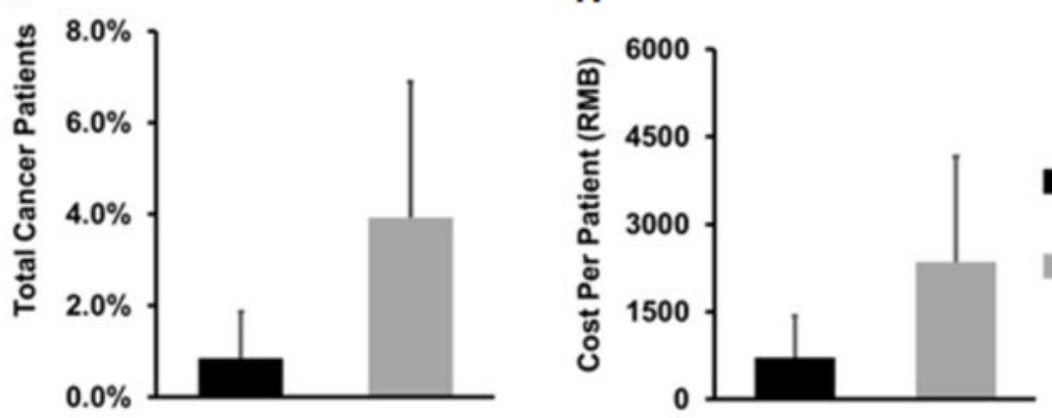

CPMs in oral dosage

forms $(n=27)$

CPMs in injections

$(n=10)$

I

J
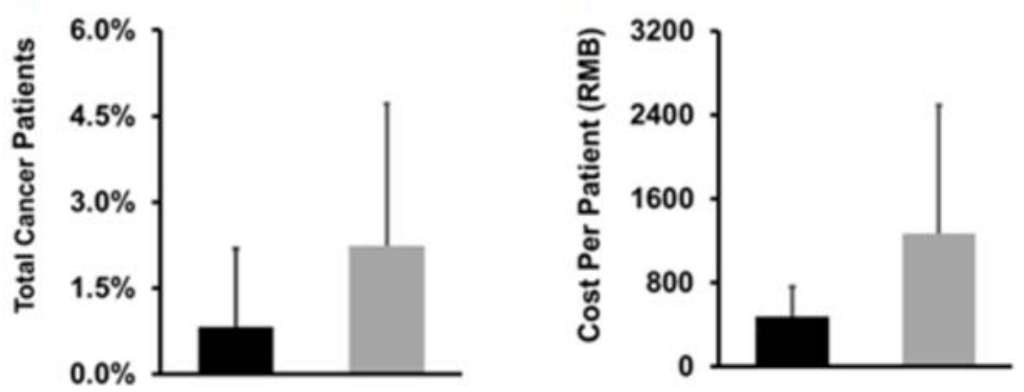

CPMs with a number of herbs and other materials $\geqq 10(n=8)$

CPMs with a number of herbs and other materials $<10(n=25)$

Figure 1: (Continued) Use rate (E) and cost (F) of individual anticancer drugs in sampled cancer patients; use rate (G) and cost per patient $(\mathrm{H})$ of anticancer CPMs in different formulations; use rate (I) and cost per patient (J) of anticancer CPMs with different numbers of raw materials.

\section{Use of individual anticancer CPMs in sampled cancer patients}

As shown in Fig. 1E-1J, the use rate (mean 1.9\%) of individual anticancer CPMs in 51,382 cancer patients was significantly higher than that of individual anticancer WMs (mean 1.6\%) $(P=0.017)$. There was no significant difference in the cost between individual anticancer CPMs (mean, 1.37 million RMB per drug) and that of individual anticancer WMs (mean, 1.29 million RMB per drug) $(P=0.069)$. Moreover, in subtypes of the anticancer CPMs, the use rate and cost of the CPMs injections or CPMs with less than 10 raw materials were significantly higher than those of oral formulations, or those with over 10 raw materials, respectively (all $P<0.05$ ). The number of raw materials contained in an anticancer CPM was found to be significantly and negatively correlated with its usage (correlation coefficient $=-0.449, P=0.009$; see data and diagram in Table S3).

\section{Raw materials and efficacy of commonly used anticancer CPMs}

By calculating the total use frequency of 33 anticancer CPMs with the same materials, the 10 mostly used raw materials are Huang-Qi (Astragali Radix), RenShen (Ginseng Radix Et Rhizoma), Ku-Shen (Sophorae Flavescentis Radix), Ban-Mao (Mylabris), Ci-Wu-Jia (Acanthopanacis Senticosi Radix Et Rhizoma Seu Caulis), Dang-Shen (Codonopsis Pilosula), Nv-Zhen-Zi (Ligustri Lucidi Fructus), Tu-Fu-Ling (Smilacis Glabrae Rhizoma), Ban-Zhi-Lian (Scutellariae Barbatae Herba), and Ya-Dan$\mathrm{Zi} \mathrm{(Bruceae} \mathrm{Fructus).} \mathrm{The} \mathrm{therapy} \mathrm{effects} \mathrm{of} \mathrm{anticancer}$ CPMs are mainly expressed as two types of traditional efficacy in their instructions. One is "eliminating pathogen" ( $Q u$-Xie in Chinese) labeled as clearing away hot, relieving blood stasis, removing toxin, etc. for those Antitumor CPMs. For instance, all top 3 antitumor CPMs have an efficacy of clearing away hot. The other is "strengthening 
body resistance" (Fu-Zheng in Chinese) labeled as tonifying Qi, nourishing yin, etc. for those Adjuvant antitumor CPMs. Table 1 listed the individual efficacy of top 15 anticancer CPMs with use frequency more than 500 patients.

We noticed that CPMs in two NBMIDC subcategories have overlapping raw materials. For example, in top 15 anticancer CPMs, five adjuvant antitumor CPMs and two antitumor CPMs (Aidi Injection and Fufangbanmao Capsule) has a herb material Huang-Qi (Astragali Radix). Both an antitumor CPM (Fufangkushen Injection) and an adjuvant antitumor CPM (Kangai Injection) contain the herb Ku-Shen (Sophorae Flavescentis Radix). These CPMs showed similar applicable indications (Fig. 2). Moreover, five antitumor CPMs including Aidi Injection and Fufangbanmao Capsule contain toxic materials indicated in China's Pharmacopoeia or literature (Table 1), which may reflect the TCM idea of "fighting poison with poison".

\section{Cancer profile of anticancer CPMs and WMs by bi-clustering analysis}

Anticancer CPMs tended to be used for a broad spectrum of top 17 cancers (Fig. 3A). Few of these (Huaier, Jinlong, Ganfule and Zilongjin) showed selectivity but had a relatively low use rate $(<6 \%)$ in the specific cancers. The top two frequently used anticancer CPMs (Shenqifuzheng injection and Fufangkushen injection) were used for almost all 17 types of cancers. By contrast, anticancer WMs were more specific in cancer therapy (Fig. 3B). Meanwhile, anticancer WMs for liver and kidney cancers were used at a lower rate than those for other cancers. Table S4 showed 22 anticancer WMs with use frequency more than 500 patients.

\section{Individual anticancer medicines for top 17 cancers}

Individually, anticancer CPMs do not dominate the cancer therapy. The top use rate of individual anticancer CPMs in 17 cancers except liver and kidney cancers was much lower than that of anticancer WMs (Table 2). The highest use rate of the CPMs in 17 cancers was Fufangkushen injection in nasopharynx and pancreas cancers $(12 \%)$, $a$ value much lower than that of individual anticancer WMs (45\% for Cytarabine in leukaemia unspecified). Furthermore, the most commonly used WM for stomach cancer was a regimen of Oxaliplatin/Fluorouracil/LV, whereas the NCCN guideline (Version 1.2008) recommended 5-FU, Capecitabine, ECF (Epirubicin/Cisplatin/Fluorouracil) or DCF (Docetaxel/Cisplatin/Fluorouracil), based on high-level evidence. The top two anticancer WMs commonly used for bladder cancer (Pirarubicin and Hydroxycamptothecin) in current data were absent in NCCN guideline (Version 1.2008).
Table 3 illustrates the mean and maximum use rate of anticancer CPMs and WMs in top 17 cancers, respectively. The coefficient of the variation (CV) value, characterizing the extent of variability of the use rate of anticancer CPMs, ranged from $24 \%$ to $93 \%$, with a mean of $49 \%$. This result was significantly lower than that of anticancer WMs, which ranged from $97 \%$ to $255 \%$, with a mean of $152 \%$. The results once again indicated less selectivity of anticancer CPMs in cancer therapy.

\section{Combined use networks of anticancer CPMs and WMs}

In this survey, a total of $12,743(24.8 \%)$ patients used both anticancer CPMs and WMs simultaneously during their hospital stays. To obtain the combined use patterns of both medicines, a CPM-WM combined use network for four major cancers in China was constructed (Fig. 4). Among the high frequent combinations, adjuvant antitumor CPMs were more commonly used in conjunction with WMs in treating lung cancer. The gastrointestinal cancers, in particular stomach and colorectal cancers, shared similar combination profiles, in which CPMs tended to band together with the first line WM regimens, such as FOLFOX4. Meanwhile, adjuvant antitumor CPMs including Shenqifuzheng injection and antitumor CPMs including Aidi injection were involved in all four cancers together with WMs. Parts of these CPM-WM combinations were supported by clinical evidence as reported (Table S5).

\section{DISCUSSION}

This nationwide analysis characterizes how CPMs are used to fight cancer in China. In general, anticancer CPMs have gained increased popularity and been used in almost half (42.4\%) of investigated cancer patients. The cost per patient for all anticancer CPMs is lower than that of anticancer WMs. We found that CPMs with less raw materials are relatively more popular in treating cancers (Fig. 1; Table S3). This is partly due to CPM injections that usually composed of less raw materials are used more commonly than other CPMs. And the less raw materials may make the CPMs easier to understand and more acceptable for clinicians. Compared with 71 anticancer WMs, the use rate of 33 anticancer CPMs was higher than in liver, kidney, pancreatic, and esophagus cancers. There are two probable reasons. Firstly, these four cancers may have less specific and effective anticancer WMs than other cancers, leading to a lower use rate of anticancer WMs. Secondly, some first line drugs for the liver cancer and kidney cancer such as Sorafenib and Sunitinib were not covered by NBMIDC, making the use rate of anticancer WMs much lower in liver cancer (29\%) and 
Table 1: Raw materials, labeled efficacy, and use frequency of top 15 anticancer CPMs used in cancer patients ( $>500$ cases)

\begin{tabular}{|c|c|c|c|c|}
\hline CPM name & $\begin{array}{l}\text { NBMIDC } \\
\text { subcategory }\end{array}$ & Raw material & Labeled efficacy & $\begin{array}{l}\text { Use } \\
\text { frequency }\end{array}$ \\
\hline $\begin{array}{l}\text { Shenqifuzheng } \\
\text { Injection }\end{array}$ & $\begin{array}{l}\text { Adjuvant antitumor } \\
\text { CPM }\end{array}$ & $\begin{array}{l}\text { Astragali Radix, } \\
\text { Codonopsis Pilosula }\end{array}$ & $\begin{array}{l}\text { Tonifying Qi and strengthening } \\
\text { body resistance }\end{array}$ & 4114 \\
\hline $\begin{array}{l}\text { Fufangkushen } \\
\text { Injection }\end{array}$ & Antitumor CPM & $\begin{array}{l}\text { Sophorae Flavescentis } \\
\text { Radix, Smilacis Glabrae } \\
\text { Rhizoma }\end{array}$ & $\begin{array}{l}\text { Clearing away hot, removing } \\
\text { dampness, cooling blood, } \\
\text { removing toxin, resolving hard } \\
\text { mass, and relieving pain }\end{array}$ & 3931 \\
\hline Aidi Injection & Antitumor CPM & $\begin{array}{l}\text { Mylabris*, Ginseng } \\
\text { Radix Et Rhizoma, } \\
\text { Astragali Radix, } \\
\text { Acanthopanacis } \\
\text { Senticosi Radix Et } \\
\text { Rhizoma Seu Caulis }\end{array}$ & $\begin{array}{l}\text { Clearing away hot, removing } \\
\text { toxin, resolving stagnation and } \\
\text { dispersing masses }\end{array}$ & 3761 \\
\hline $\begin{array}{l}\text { Yadanziyou Injection } \\
\text { (Oral emulsion, Soft } \\
\text { capsule) }\end{array}$ & Antitumor CPM & Bruceae Fructus* & $\begin{array}{l}\text { Antitumor; (Herb efficacy: } \\
\text { Clearing away hot and } \\
\text { removing toxin) }\end{array}$ & 2683 \\
\hline Kangai Injection & $\begin{array}{l}\text { Adjuvant antitumor } \\
\text { CPM }\end{array}$ & $\begin{array}{l}\text { Astragali Radix, Ginseng } \\
\text { Radix Et Rhizoma, } \\
\text { Sophorae Flavescentis } \\
\text { Radix }\end{array}$ & $\begin{array}{l}\text { Tonifying Qi and strengthening } \\
\text { body resistance }\end{array}$ & 2515 \\
\hline $\begin{array}{l}\text { Fufangbanmao } \\
\text { Capsule }\end{array}$ & Antitumor CPM & $\begin{array}{l}\text { Mylabris*, Ginseng } \\
\text { Radix Et Rhizoma, } \\
\text { Astragali Radix, } \\
\text { Acanthopanacis } \\
\text { Senticosi Radix Et } \\
\text { Rhizoma Seu Caulis, } \\
\text { Sparganii Rhizoma, } \\
\text { Scutellariae Barbatae } \\
\text { Herba, Curcumae } \\
\text { Rhizoma, Corni Fructus, } \\
\text { Ligustri Lucidi Fructus, } \\
\text { fel ursi, Glycyrrhizae } \\
\text { Radix }\end{array}$ & $\begin{array}{l}\text { Relieving blood stasis, } \\
\text { resolving stagnation, removing } \\
\text { toxin, and corroding sores }\end{array}$ & 2098 \\
\hline $\begin{array}{l}\text { Zhenqifuzheng } \\
\text { Granule (Capsule, } \\
\text { Tablet) }\end{array}$ & $\begin{array}{l}\text { Adjuvant antitumor } \\
\text { CPM }\end{array}$ & $\begin{array}{l}\text { Astragali Radix, Ligustri } \\
\text { Lucidi Fructus }\end{array}$ & $\begin{array}{l}\text { Tonifying Qi and nourishing } \\
\text { yin }\end{array}$ & 1871 \\
\hline $\begin{array}{l}\text { Huachansu Injection } \\
\text { (Capsule, Tablet) }\end{array}$ & Antitumor CPM & Bufonis Corium* & $\begin{array}{l}\text { Removing toxin, detumescence, } \\
\text { and relieving pain }\end{array}$ & 1387 \\
\hline $\begin{array}{l}\text { Xiaoaiping Injection } \\
\text { (Oral formulations) }\end{array}$ & Antitumor CPM & $\begin{array}{l}\text { Marsdenia tenacissima } \\
\text { Caulis }\end{array}$ & $\begin{array}{l}\text { Antitumor, anti-inflammatory, } \\
\text { and antiasthmatic }\end{array}$ & 1339 \\
\hline Fufangzaofan Pill & $\begin{array}{l}\text { Adjuvant antitumor } \\
\text { CPM }\end{array}$ & $\begin{array}{l}\text { Melanteritum, } \\
\text { Panacis Quinquefolii } \\
\text { Radix, Hippocampus, } \\
\text { Cinnamomi Cortex, } \\
\text { Jujubae Fructus, } \\
\text { Juglandis Semen }\end{array}$ & $\begin{array}{l}\text { Warming kidney, tonifying } \\
\text { marrow, Qi, yin and blood, and } \\
\text { stanching bleeding }\end{array}$ & 1191 \\
\hline
\end{tabular}

(Continued) 


\begin{tabular}{|c|c|c|c|c|}
\hline CPM name & $\begin{array}{l}\text { NBMIDC } \\
\text { subcategory }\end{array}$ & Raw material & Labeled efficacy & $\begin{array}{c}\text { Use } \\
\text { frequency }\end{array}$ \\
\hline Huangqi Injection & $\begin{array}{l}\text { Adjuvant antitumor } \\
\text { CPM }\end{array}$ & Astragali Radix & $\begin{array}{l}\text { Tonifying Qi and strengthening } \\
\text { body resistance, pulse- } \\
\text { invigorating and heart- } \\
\text { nourishing, fortifying spleen } \\
\text { and disinhibiting dampness }\end{array}$ & 943 \\
\hline $\begin{array}{l}\text { Pingxiao Capsule } \\
\text { (Tablet) }\end{array}$ & Antitumor CPM & $\begin{array}{l}\text { Curcumae Radix, } \\
\text { Agrimoniae Herba, } \\
\text { Trogopterori Faeces, } \\
\text { Alumen, Nitrum, } \\
\text { Toxicodendri Resina*, } \\
\text { Aurantii Fructus, } \\
\text { Strychni Semen } \\
\text { Pulveratum* } \\
\end{array}$ & $\begin{array}{l}\text { Promoting blood circulation for } \\
\text { removing blood stasis, relieving } \\
\text { pain, resolving mass, clearing } \\
\text { away hot, removing toxin, } \\
\text { strengthening body resistance, } \\
\text { and eliminating pathogen }\end{array}$ & 762 \\
\hline $\begin{array}{l}\begin{array}{l}\text { Kanglaite Injection } \\
\text { (Soft Capsule) }\end{array} \\
\end{array}$ & Antitumor CPM & Jobstears Seed Oil & $\begin{array}{l}\text { Tonifying Qi, nourishing yin, } \\
\text { and resolving mass }\end{array}$ & 628 \\
\hline $\begin{array}{l}\text { Fermental Preparation } \\
\text { of Chongcaojun }\end{array}$ & $\begin{array}{l}\text { Adjuvant antitumor } \\
\text { CPM }\end{array}$ & Cordyceps & $\begin{array}{l}\text { Supplementing lung and } \\
\text { kidney, and tonifying } \\
\text { essence Qi }\end{array}$ & 624 \\
\hline Yixuesheng Capsule & $\begin{array}{l}\text { Adjuvant antitumor } \\
\text { CPM }\end{array}$ & $\begin{array}{l}\text { Asini Corii Colla, } \\
\text { Testudinis Carapacis } \\
\text { et Plastri Colla, Cervi } \\
\text { Cornus Colla, Deer } \\
\text { blood, Beef marrow, } \\
\text { Hominis Placenta, Cervi } \\
\text { Cornu Pantotrichum, } \\
\text { Poria, Astragali Radix } \\
\text { Praeparata Cum Melle, } \\
\text { Paeoniae Radix Alba, } \\
\text { Polygoni Multiflori Radix } \\
\text { Praeparata, Jujubae } \\
\text { Fructus, Crataegi } \\
\text { Fructus, Hordei Fructus } \\
\text { Germinatus, Galli } \\
\text { Gigerii Endothelium } \\
\text { Corneum, Anemarrhenae } \\
\text { Rhizoma, Rhei Radix et } \\
\text { Rhizom, Testa Arachidis }\end{array}$ & $\begin{array}{l}\text { Spleen invigorating and kidney } \\
\text { nourishing, replenishing blood, } \\
\text { supplying essences }\end{array}$ & 548 \\
\hline
\end{tabular}

*Toxic materials indicated in China's Pharmacopoeia or literature.

kidney cancer (17\%). By contrast, the anticancer CPMs are widely used in various cancers, and thus showing a relatively higher rate in these four cancers especially in liver and kidney cancers.

In this study, a "widespread and dispersive" charateristic with low selectivity for the use of anticancer CPMs has been revealed (Table 2, Table 3 and Fig. 3). Although the mean usage of anticancer CPMs was significantly higher than their western counterparts, the use rates of top anticancer CPMs (no more than $12 \%$ ) were much lower than those of top WMs (a maximum of $45 \%$ ) in 17 main cancers except kidney cancer (Table 2). The results suggest the individual anticancer CPMs are not dominant in a specific cancer treatment. One possible reason is that CPMs always regulate overall health of human body rather than simply fight against a specific cancer. A typical case is Shenqifuzheng injection, the most often used adjuvant antitumor CPM. This injection, broadly used for almost all 17 cancers, is composed of Huang-Qi (Astragali Radix) and Dang-Shen (Codonopsis Pilosula). Both of the two herbs contain immunomodulatory ingredients, and can improve the immune function of cancer patients receiving chemotherapy [11-14]. Thus, Shenqifuzheng injection could be widely used as an efficacious adjuvant 
A CPMs containing Astragali Radix

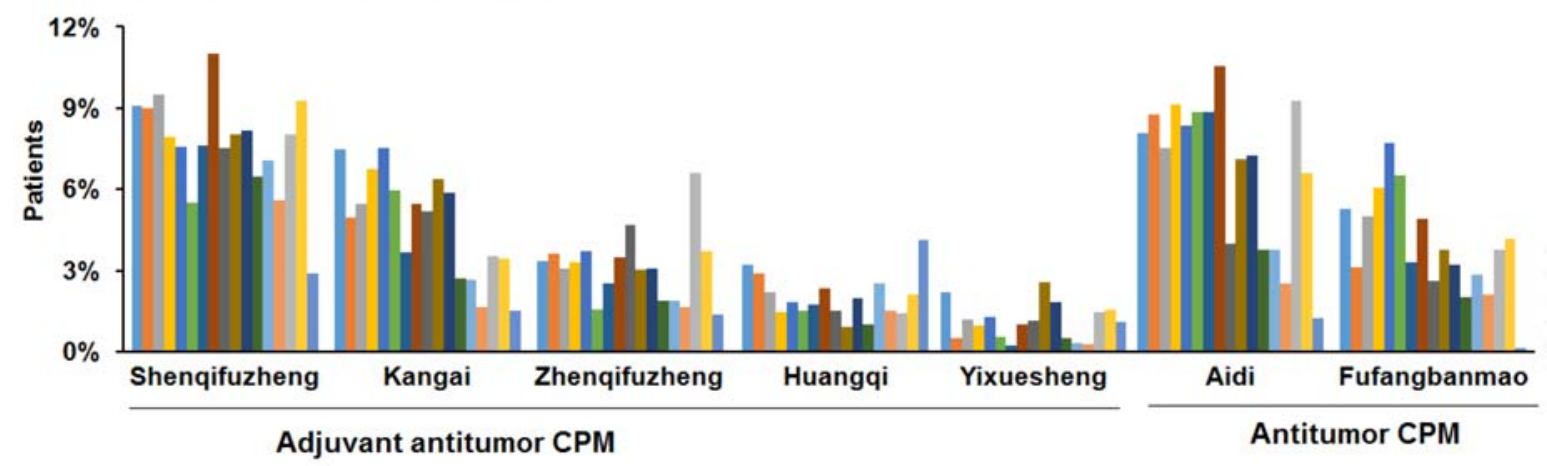

B CPMs containing Sophorae Flavescentis Radix

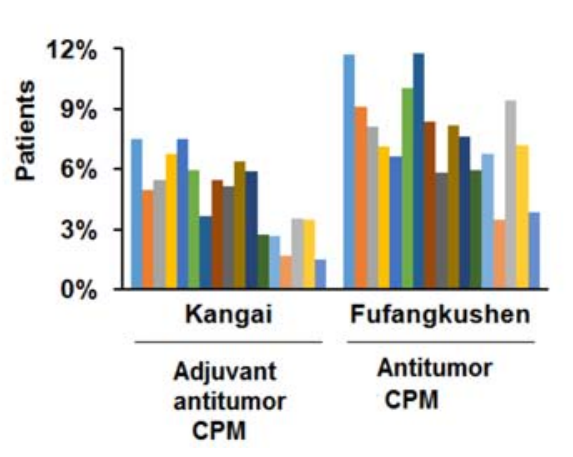

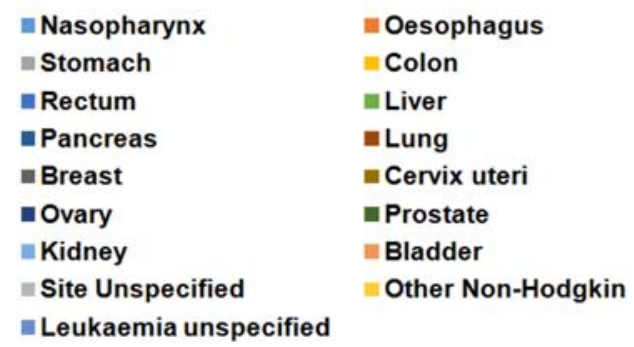

Figure 2: Use frequency of seven CPMs containing Astragali Radix (A) and two CPMs containing Sophorae Flavescentis Radix (B) that in both "antitumor" and "adjuvant antitumor" subcategories of CPM.

to prevent immunity impairment that usually occurs in therapy of various cancers. Another reason for the low selectivity of CPMs is that the precise efficacy of CPMs is not quite clear in clinical use. Anticancer CPMs mainly labeled their traditional efficacy (Table 1). However, the applicable cancer type was not clearly stated in instructions or just indicated as "et al." or "advanced cancers" for many CPMs. Thus, the specific and evidence-based indications are still required to improve the rational use of CPMs. This study also indicates the subcategory classification of CPMs in NBMIDC needs to be further clarified, since both CPM subcategories have similar clinical use patterns and overlapped herb materials such as Astragali Radix (an immunomodulatory herb [11,12]) and Sophorae Flavescentis Radix (an anti-tumor herb [15,16]) (Fig. 2). Special safety caution should also be paid to CPM injections and CPMs containing toxic ingredients.

The CPMs and WMs are commonly used in combination and work in concert for cancer treatment. Most of the herb-drug pairs identified by our network analysis (Fig. 4) have clinical evidence (Table S5), often reported as improving quality of life of patients and reducing adverse reactions of chemotherapy. Thus, CPMs may offer potential therapeutic benefits for cancer patients by boosting efficiency and decreasing toxicity caused by WMs. Other herb-drug pairs lacking of references deserve further investigation. More solid evidence and whether new safety risks can be generated from the herb-drug interactions needs further studies. A standard program will be of great significance to guide the combined use of CPMs and WMs.

Although our data only catch sampled patients in China and the results need to be validated in larger samples, this analysis for the first time addressed the clinical use of anticancer CPMs in a China nationwide. This study provides valuable information to improve the standardization, rationalization and internationalization of the clinical use of Chinese medicines.

\section{MATERIALS AND METHODS}

\section{National-wide sampling}

Data was from a nationwide survey for inpatients' utilization of health services covered by China's urban basic medical insurance from 2008 to 2010. All patients were firstly sorted by discharge time and then randomly sampled from China's 29 provincial-level administrative regions. The inpatients came from 2,576 hospitals in 22 provinces, 3 autonomous regions, and 4 centrally-administered municipalities. The percentage of the sampled inpatients who had medical insurance coverage was $2 \%$ in the centrallyadministered municipalities and provincial capitals, $5 \%$ in the prefecture-level cities, and $10 \%$ in the counties. 


\section{Drugs and cancer patients' data}

The drugs, medication records and cost for 51,382 malignant tumor inpatients, including 11209 cases $(21.8 \%)$ in 2008,16850 cases $(32.8 \%)$ in 2009 , and 23323 cases $(45.4 \%)$ in 2010 , were retrieved from the sampling data. The data on two types of drugs were collected, including CPMs (registered and approved by China State Food and
Drug Administration) and WMs (all modern medicines including saline, glucose and other auxiliary drugs).

\section{NBMIDC recorded anticancer CPMs and WMs}

A total of NBMIDC-covered 33 anticancer CPMs (calculated by the number of generic names after different dosage forms were merged) and 71 anticancer WMs

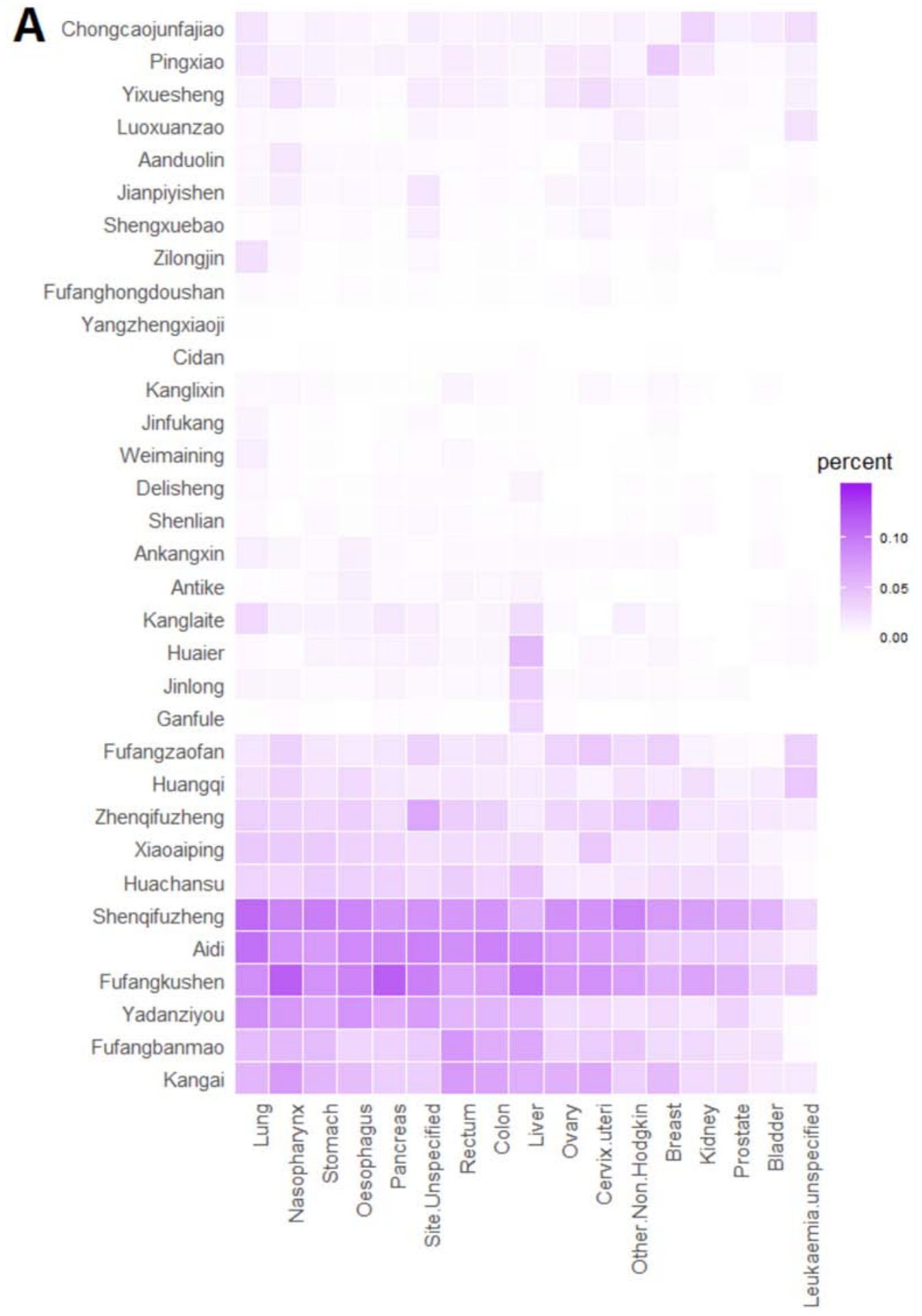

(Continued) 


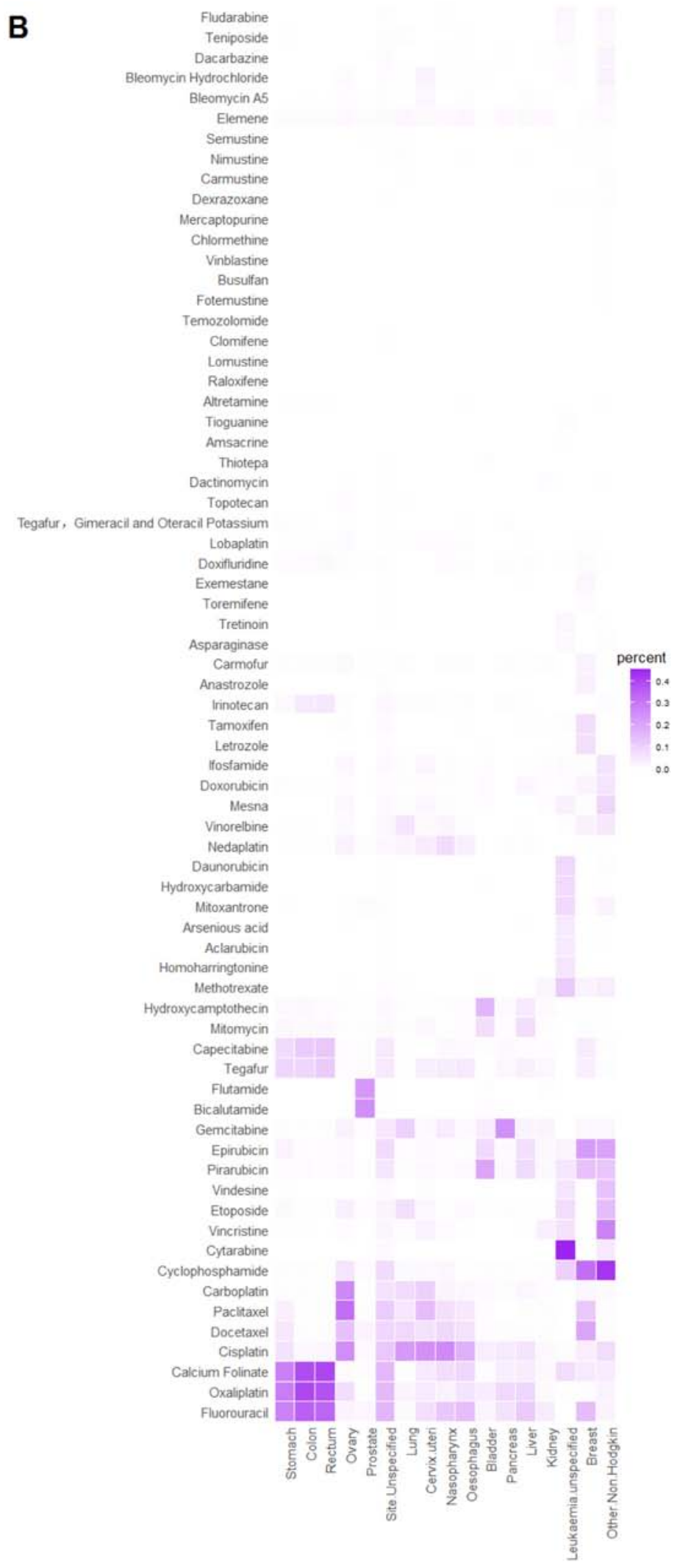

\section{Figure 3: Cancer profiles of anticancer CPMs (A) and anticancer WMs (B)}

(calculated by the number of generic names of the active pharmaceutical ingredients) were used in sampled cancer patients. For anticancer CPMs, 17 fall into the NBMIDC
"Antitumor" subcategory and 16 into the "Adjuvant antitumor" subcategory. The number of raw materials (herbs, animals or others) contained in each anticancer CPMs ranges 


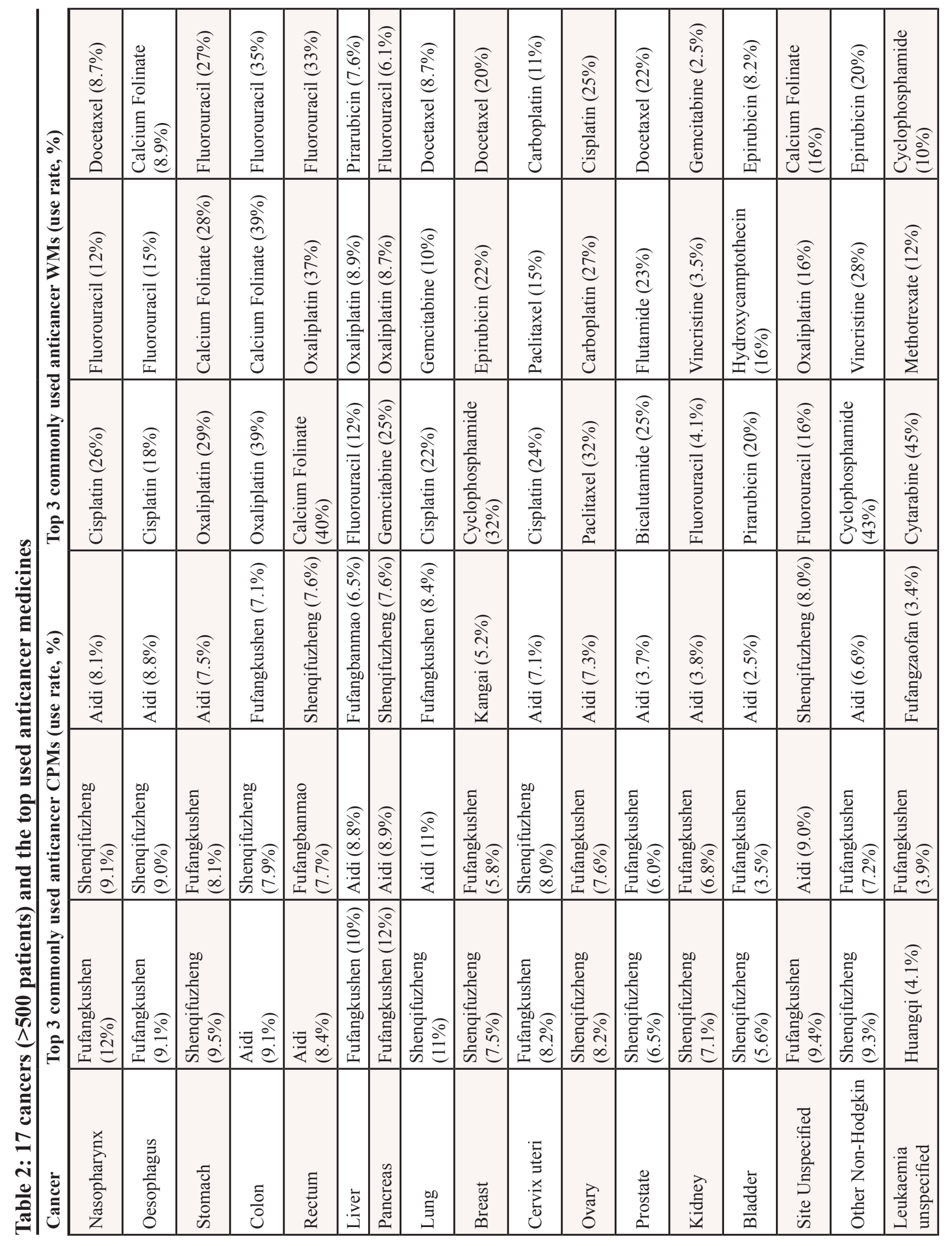


Table 3: Use rate of individual anticancer medicine in 17 cancers ( $>500$ patients)

\begin{tabular}{|c|c|c|c|c|c|}
\hline \multirow[t]{2}{*}{ Drugs } & \multirow[t]{2}{*}{ Category } & \multirow[t]{2}{*}{ Maximum rate (cancer) } & \multicolumn{3}{|c|}{ Use rate in 17 cancers } \\
\hline & & & Mean & $\mathbf{C V}$ & Mean of CV \\
\hline Shenqifuzheng & CPM & $11.0 \%$ (Lung) & $7.7 \%$ & $24 \%$ & $49 \%$ \\
\hline Fufangkushen & CPM & $11.8 \%$ (Pancreas) & $7.7 \%$ & $30 \%$ & \\
\hline Aidi & CPM & $10.6 \%$ (Lung) & $6.8 \%$ & $40 \%$ & \\
\hline Kangai & CPM & $7.5 \%$ (Rectum) & $4.7 \%$ & $40 \%$ & \\
\hline Yadanziyou & CPM & $8.2 \%$ (Lung) & $4.5 \%$ & $57 \%$ & \\
\hline Fufangbanmao & CPM & 7.7\% (Rectum) & $3.9 \%$ & $48 \%$ & \\
\hline Zhenqifuzheng & CPM & $6.6 \%$ (Site Unspecified) & $3.1 \%$ & $42 \%$ & \\
\hline Huachansu & $\mathrm{CPM}$ & $4.7 \%$ (Liver) & $2.5 \%$ & $43 \%$ & \\
\hline Xiaoaiping & CPM & $4.1 \%$ (Cervix uteri) & $2.5 \%$ & $46 \%$ & \\
\hline Fufangzaofan & CPM & $4.1 \%$ (Cervix uteri) & $2.2 \%$ & $51 \%$ & \\
\hline Huangqi & CPM & 4.1\% (Leukaemia unspecified) & $2.0 \%$ & $41 \%$ & \\
\hline Pingxiao & CPM & $3.9 \%$ (Breast) & $1.3 \%$ & $61 \%$ & \\
\hline Kanglaite & CPM & $2.8 \%$ (Lung) & $0.9 \%$ & $93 \%$ & \\
\hline Chongcaojunfajiao & $\mathrm{CPM}$ & $3.1 \%$ (Kidney) & $1.2 \%$ & $57 \%$ & \\
\hline Yixuesheng & CPM & $2.6 \%$ (Cervix uteri) & $1.1 \%$ & $61 \%$ & \\
\hline Fluorouracil & WM & $34.9 \%$ (Colon) & $11.4 \%$ & $99 \%$ & $152 \%$ \\
\hline Oxaliplatin & WM & $39.2 \%$ (Colon) & $10.0 \%$ & $127 \%$ & \\
\hline Calcium Folinate & WM & $39.6 \%$ (Rectum) & $10.0 \%$ & $129 \%$ & \\
\hline Cisplatin & WM & $26.2 \%$ (Nasopharynx) & $9.8 \%$ & $97 \%$ & \\
\hline Cyclophosphamide & WM & $42.6 \%$ (Other Non-Hodgkin) & $6.2 \%$ & $196 \%$ & \\
\hline Docetaxel & WM & $20.2 \%$ (Breast) & $4.9 \%$ & $118 \%$ & \\
\hline Paclitaxel & WM & $31.9 \%$ (Ovary) & $5.5 \%$ & $152 \%$ & \\
\hline Epirubicin & WM & $22.2 \%$ (Breast) & $4.6 \%$ & $149 \%$ & \\
\hline Pirarubicin & WM & $20.0 \%$ (Bladder) & $4.3 \%$ & $136 \%$ & \\
\hline Carboplatin & WM & $26.5 \%$ (Ovary) & $3.7 \%$ & $176 \%$ & \\
\hline Gemcitabine & WM & $24.6 \%$ (Pancreas) & $3.7 \%$ & $159 \%$ & \\
\hline Tegafur & WM & $11.7 \%$ (Rectum) & $3.5 \%$ & $103 \%$ & \\
\hline Capecitabine & WM & $12.2 \%$ (Rectum) & $2.8 \%$ & $144 \%$ & \\
\hline Etoposide & WM & $14.7 \%$ (Other Non-Hodgkin) & $2.3 \%$ & $168 \%$ & \\
\hline Vinorelbine & WM & $5.8 \%$ (Lung) & $1.3 \%$ & $144 \%$ & \\
\hline Vincristine & WM & $27.6 \%$ (Other Non-Hodgkin) & $2.6 \%$ & $255 \%$ & \\
\hline Nedaplatin & WM & $7.5 \%$ (Nasopharynx) & $1.4 \%$ & $150 \%$ & \\
\hline Mitomycin & WM & 7.4\% (Bladder) & $1.4 \%$ & $158 \%$ & \\
\hline Hydroxycamptothecin & WM & $16.2 \%$ (Bladder) & $1.7 \%$ & $221 \%$ & \\
\hline Irinotecan & WM & $5.0 \%$ (Rectum) & $0.9 \%$ & $169 \%$ & \\
\hline
\end{tabular}




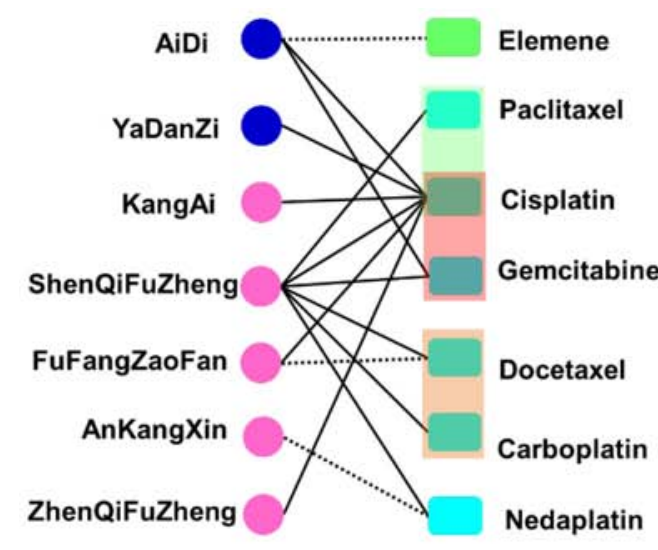

Lung cancer

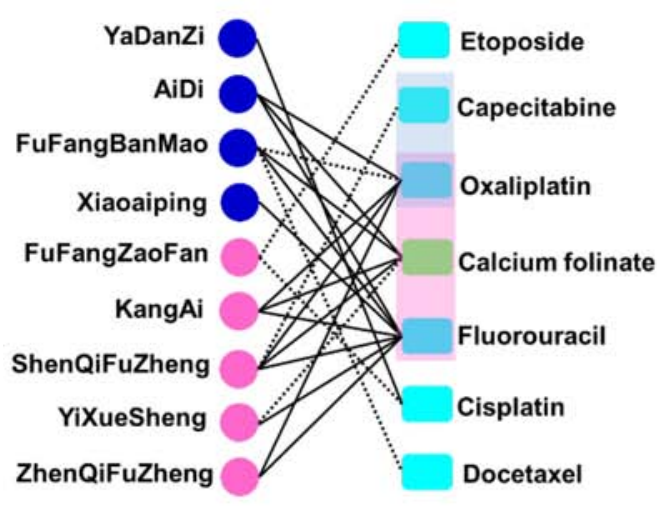

Stomach cancer

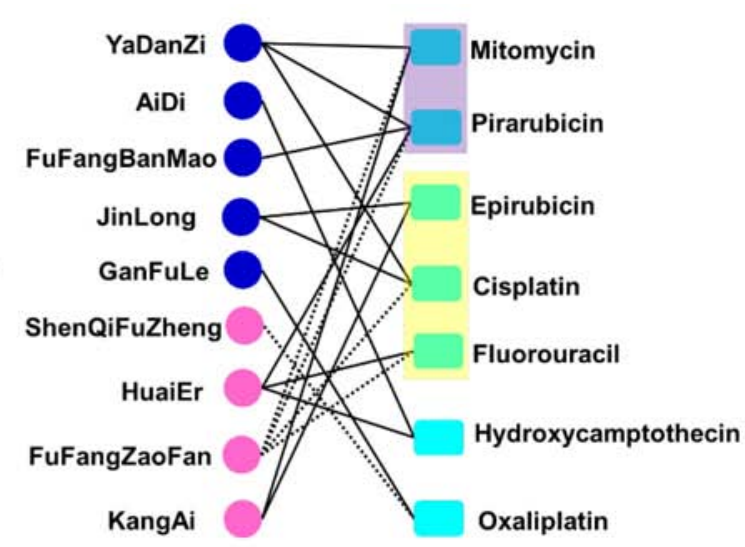

Liver cancer

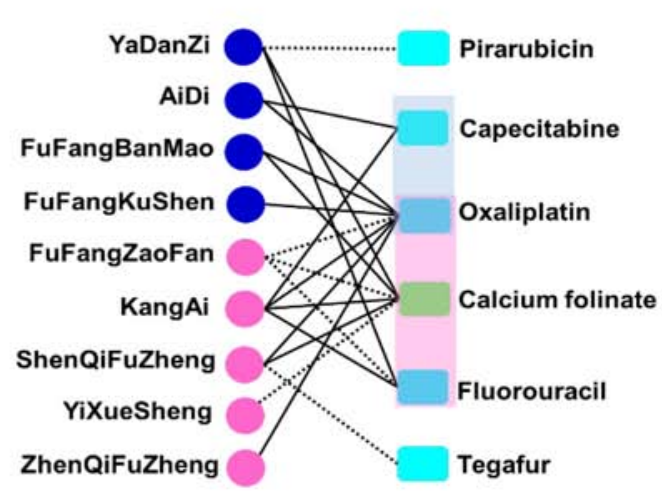

Colorectal cancer

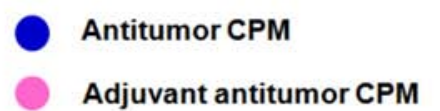

Anticancer $\mathrm{WM}$ and regimens

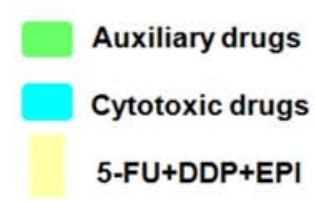

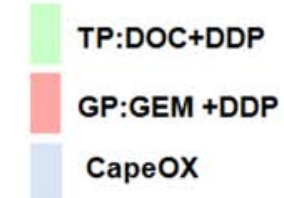

FOLFOX

TC:DOC+CBP

THP+MMC

Figure 4: Combined use network of anticancer CPMs and WMs in four major cancers. The combined links in networks marked with the full lines were supported by clinical evidence (Table S5), and those with the dotted lines lacked clinical reports.

from 1 to 22, and 124 materials get involved. Anticancer WMs include 56 cytotoxic, 9 hormone, 4 auxiliary and 2 other drugs.

\section{Statistical, bi-clustering, and network analysis}

Use-frequency of a drug (CPM or WM) refers to the total number of patients in which a drug was used in the medication records. Use rate of a drug was the percentage of the total cancer patients or patients with a specific cancer who used the drug. Cost ratio means Ratio of the total drug cost. A Mann-Whitney rank sum test was used to evaluate the statistical significance of the use rate and cost between the anticancer CPMs and anticancer WMs, as well as a comparison analysis for different types of anticancer CPMs. A Spearman rank correlation analysis was used to analyze the correlation between the rank of use rates and the rank of number of raw materials contained in each anticancer CPMs.

Bi-clustering method was used to analyze the cancer profile of anticancer CPMs and WMs. A bipartite graph was first created for drugs and various types of cancers, in which nodes denoted drugs or cancers, and edges denoted the use of a drug for a particular cancer. The weights 
of edges were expressed as the use rate of drug, which represented the percentage of patients with a certain cancer who used drug. Then, hierarchical clustering was performed for drugs using all of the row vectors to cluster together similar drugs. Similarly, hierarchical clustering was performed for the various types of cancers to cluster together similar cancers. The order of drugs and cancers was adjusted according to the results of the clustering and a heat map was generated.

A network approach was used to analyze the combined use of CPMs and WMs [17]. The network nodes represented drugs, and the edges represented the combined relationship between two drugs. The combined relationship was measured by two indicators. One was the frequency of the combined use, which referred to the number of cancer patients who used drugs in combination. The other was the mutual information entropy [17]. The effective combined relationships were screened (total number of combined use $>50$ times, or total combined mutual information $>0.005$ ) for constructing CPM-WM combined use networks (see Supplementary text).

\section{ACKNOWLEDGMENTS}

We thank China Health Insurance Research Association affiliated with the Ministry of Human Resources and Social Security of China for providing data.

\section{GRANT SUPPORT}

This work is partly supported by National Natural Science Foundation of China (81225025 and 91229201).

\section{CONFLICTS OF INTEREST} authors.

There are no conflict of interest disclosures from any

\section{REFERENCES}

1. Normile D. Asian medicine: The new face of traditional Chinese medicine. Science. 2003; 299:188-190.

2. Ministry of Human Resources and Social Security of the People's Republic of China. China's National Basic Medical Insurance, Work Injury Insurance and Maternity Insurance Drugs Catalog (2009 edition). China Labour and Social Security Publishing House. 2009; 12-1.

3. Tong B, Ding N, Wei Q. Analysis of the Utilization of Antineoplastic Agents in Our Hospitals during the Period of 2009-2011. China Pharmacy. 2012; 23:3960-3963.

4. Wang J, Lu M, Zhang G, Lu H. Utilization of Antitumor Drugs in Changshu Hospital Affiliated to Soochow University during 2010-2013. Evaluation and analysis of drug-use in hospitals of China. 2014; 14:908-912.
5. Xu Y, Wang X, Luan W. Analysis on Drug Use in PLA General Hospital During 2008-2010. Evaluation and analysis of drug-use in hospitals of China. 2012; 12:109-113.

6. Wang CY, Bai XY, Wang CH. Traditional Chinese medicine: a treasured natural resource of anticancer drug research and development. Am J Chin Med. 2014; 42:543-59.

7. Liang $\mathrm{X}, \mathrm{Li} \mathrm{H}, \mathrm{Li} \mathrm{S}$. A novel network pharmacology approach to analyse traditional herbal formulae: the Liuwei-di-huang Pill as a case study. Molecular BioSystems. 2014; 10:1014-1022.

8. Adepoju L, Wanjiku S, Brown M, Qu W, Williams M, Redfern RE, Sferra JJ. Effect of insurance payer status on the surgical treatment of early stage breast cancer: data analysis from a single health system. JAMA Surg. 2013; 148:570-2.

9. Robbins AS, Pavluck AL, Fedewa SA, Chen AY, Ward EM. Insurance status, comorbidity level, and survival among colorectal cancer patients age 18 to 64 years in the National Cancer Data Base from 2003 to 2005. J Clin Oncol. 2009; 27:3627-33.

10. Chen W, Zhang S, Zheng R, Zeng H, Zou X, Zhao P, Wu L, Li G, Hao J. Report of Cancer Incidence and Mortality in China, 2009. China Cancer. 2013; 22:2-12.

11. Kang H, Ahn KS, Cho C, Bae HS. Immunomodulatory effect of Astragali Radix extract on murine TH1/TH2 cell lineage development. Biol Pharm Bull. 2004; 27:1946-50.

12. Lee YS, Han OK, Park CW, Suh SI, Shin SW, Yang CH, Jeon TW, Lee ES, Kim KJ, Kim SH, Yoo WK, Kim HJ. Immunomodulatory effects of aqueous-extracted Astragali radix in methotrexate-treated mouse spleen cells. J Ethnopharmacol. 2003; 84:193-8.

13. Zeng XL, Li XA, Zhang BY. Immunological and hematopoietic effect of Codonopsis pilosula on cancer patients during radiotherapy. Zhongguo Zhong Xi Yi Jie He Za Zhi. 1992; 12:607-8. 581.

14. Zhuang SR, Chen SL, Tsai JH, Huang CC, Wu TC, Liu WS, Tseng HC, Lee HS, Huang MC, Shane GT, Yang CH, Shen YC, Yan YY, Wang CK. Effect of citronellol and the Chinese medical herb complex on cellular immunity of cancer patients receiving chemotherapy/radiotherapy. Phytother Res. 2009; 23:785-790.

15. Wang Z, Zhang J, Wang Y, Xing R, Yi C, Zhu H, Chen X, Guo J, Guo W, Li W, Wu L, Lu Y, Liu S. Matrine, a novel autophagy inhibitor, blocks trafficking and the proteolytic activation of lysosomal proteases. Carcinogenesis. 2013; 34:128-138.

16. Xie SB, He XX, Yao SK. Matrine-induced autophagy regulated by $\mathrm{p} 53$ through AMP-activated protein kinase in human hepatoma cells. Int J Oncol. 2015; 47:517-26.

17. Li S, Zhang B, Jiang D, Wei YY, Zhang NB. Herb network construction and co-module analysis for uncovering the combination rule of traditional Chinese herbal formulae. BMC Bioinformatics. 2010; 11:S6. 